\title{
Correction to: Kinetics of irreversible pore formation under constant electrical tension in giant unilamellar vesicles
}

\author{
Md. Kabir Ahamed ${ }^{1} \cdot$ Mohammad Abu Sayem Karal $^{1}$ (D) $\cdot$ Marzuk Ahmed $^{1} \cdot$ Shareef Ahammed $^{1}$
}

Published online: 26 June 2020

(c) European Biophysical Societies' Association 2020

\section{Correction to: European Biophysics Journal} https://doi.org/10.1007/s00249-020-01440-1

Due to wrong coding usage, the text included ' 1 ' before the Eqs. (8) and (11) in the original publication of the article. The correct equations are given below:

$$
\begin{aligned}
\Delta \mu_{\mathrm{N}}^{0} & =\mu_{\mathrm{N}}^{0}(E)-\mu_{\mathrm{N}}^{0}(E=0) \\
& =\gamma a+\frac{k}{a}-2 \gamma a_{0}=\gamma \frac{\left(a-a_{0}\right)^{2}}{a} \approx \gamma a_{0} \eta^{2}=\frac{a_{0}}{16 \gamma} \sigma_{\mathrm{c}}^{2}
\end{aligned}
$$

$$
\begin{aligned}
U\left(r, \sigma_{\mathrm{c}}\right) & =\mu_{\mathrm{N}, \text { total }}^{0}\left(r, \sigma_{\mathrm{c}}\right)+2 \pi r \Gamma-\mu_{\mathrm{N}, \text { total }}^{0}\left(0, \sigma_{\mathrm{c}}\right) \\
& =2 \pi r \Gamma+\left(\gamma a+\frac{k}{a}-\pi r^{2} \sigma_{\mathrm{c}}\right)-\left(\gamma a+\frac{k}{a}\right) \\
& =2 \pi r \Gamma-\pi r^{2} \sigma_{\mathrm{c}}
\end{aligned}
$$

The original article has been updated.

Publisher's Note Springer Nature remains neutral with regard to jurisdictional claims in published maps and institutional affiliations. 